\title{
Effects of Strain Rate and Temperature on the Deformation and Fracture Behaviour of Titanium Alloy
}

\author{
Su-Tang Chiou ${ }^{1,2, *}$, Hsien-Lung Tsai ${ }^{1}$ and Woei-Shyan Lee ${ }^{3}$ \\ ${ }^{1}$ Department of Mechanical Engineering, National Taiwan University of Science and Technology, \\ Taipei 106, Taiwan, R. O. China \\ ${ }^{2}$ Department of Mechanical Engineering, National United University, Miao-Li 360, Taiwan, R. O. China \\ ${ }^{3}$ Department of Mechanical Engineering, National Cheng Kung University, Tainan 701, Taiwan, R. O. China
}

The deformation response and fracture behaviour of Ti alloy under strain rates of $8 \times 10^{2} \mathrm{~s}^{-1}$ to $8 \times 10^{3} \mathrm{~s}^{-1}$ at temperatures ranging from $25^{\circ} \mathrm{C}$ to $900^{\circ} \mathrm{C}$ are studied using split-Hopkinson pressure bar. The mechanical properties and fracture features of the alloy are found to be significantly dependent on both the strain rate and the temperature. At a constant temperature, the flow stress increases with increasing strain rate. However, at a given strain rate, the flow stress reduces as the temperature increases. Furthermore, the fracture strain decreases with increasing temperature prior to phase transformation at $785^{\circ} \mathrm{C}$, but increases thereafter as the temperature is further increased. As the strain rate increases, the strain rate sensitivity increases, but the activation volume decreases. However, as the temperature increases, the strain rate sensitivity decreases and the activation volume increases. Optical microscopy (OM) and scanning electron microscopy (SEM) observations reveal that the alloy specimens fracture primarily as the result of the formation of adiabatic shear bands. The fracture surfaces of the impacted specimens exhibit both dimple-like and cleavage-like features. The density of the dimples reflects the toughness of the alloy specimen and is found to vary directly as a function of the strain rate and the temperature. [doi:10.2320/matertrans.MRA2007607]

(Received March 16, 2007; Accepted June 12, 2007; Published August 22, 2007)

Keywords: titanium alloy, strain rate and temperature effects, deformation behaviour, adiabatic shearing.

\section{Introduction}

Titanium alloys have excellent mechanical properties, including a light weight, a high specific strength, good anticorrosion resistance, and so forth. As a result, they are used in a wide variety of fields, ranging from the aerospace industry to nuclear power stations, to chemical processing plants, to medical equipment, and so on. ${ }^{1,2)}$ Ti alloy not only retains the favourable properties common to all titanium alloys, but also has a particularly high toughness characteristic, which renders it ideal for use as medical implants. ${ }^{3)}$ It is well known that material deformation mechanisms depend significantly on the operating temperature and applied strain rate. Hence, it is desirable to develop an understanding of the temperature and time-dependent aspects of the mechanical behaviour of $\mathrm{Ti}$ alloy, and of its dominant fracture mechanisms, in order to assess the ability of $\mathrm{Ti}$ components to withstand the temperature and strain rate conditions they are likely to experience in an actual service environment.

The dynamic impact properties of engineering materials are commonly evaluated using a compressive split-Hopkinson pressure bar (SHPB) system. ${ }^{4,5)}$ The literature contains a wealth of experimental data acquired using this technique for a variety of fcc, bcc and hcp metals. ${ }^{6-11)}$ In general, the results show that the flow stress of a material increases significantly with increasing strain rate. Furthermore, many studies have shown that this rate dependence effect becomes particularly pronounced at strain rates higher than $10^{3} \mathrm{~s}^{-1}$. As a result, the strain rate effect must be taken into consideration when designing structural components. Under high strain rate conditions such as those generated in high velocity impacts, high speed machining, high rate metal forming, explosive welding, armour penetration, vehicle crash testing, and so forth, the deformation of metals and alloys is characterised by

*Corresponding author, E-mail: catom@nuu.edu.tw extreme strain localisation along narrow shear bands. ${ }^{12-16)}$ The localisation of plastic flow in these shear bands commonly results in material fracture since the effect of plastic instability caused by thermal softening dominates the strain hardening effect in the deformed region. It has been reported that this plastic instability typically occurs when the rate at which heat is generated locally exceeds that at which the heat is dissipated to the surrounding material. ${ }^{17}$ )

Although several studies have explored the basic mechanical and chemical properties of $\mathrm{Ti}$ alloy, ${ }^{18-20)}$ the literature lacks a comprehensive review of the dynamic mechanical properties of this particular alloy when deformed at high strain rates over a wide temperature range. Consequently, the current study employs a split-Hopkinson pressure bar (SHPB) to establish the stress-strain response of Ti alloy under high strain rate loading conditions $\left(8 \times 10^{2} \mathrm{~s}^{-1}\right.$ to $8 \times 10^{3} \mathrm{~s}^{-1}$ ) at temperatures ranging from $25^{\circ} \mathrm{C}$ to $900^{\circ} \mathrm{C}$. The effects of the strain rate and the temperature on the mechanical properties and fracture features of the alloy are systematically examined.

\section{Experimental Procedure}

Ti alloy with a nominal composition of $1.1 \% \mathrm{Mo}, 5.2 \% \mathrm{Zr}$, $2.9 \% \mathrm{Al}, 0.35 \% \mathrm{Fe}, 0.05 \% \mathrm{~N}, 0.20 \% \mathrm{O}, 0.02 \% \mathrm{H}$ and $\mathrm{a}$ balance of $\mathrm{Ni}$ (mass) was supplied by Kobe Steel, Inc. (Japan) in STA (Solution Treatment and Aging) form. Cylindrical specimens with a height and diameter of $7 \mathrm{~mm}$ were machined using an electrodischarge machine (EDM). The specimen surfaces were polished mechanically using emery paper with a \#1500 grit size and were then buffpolished with $\mathrm{Al}_{2} \mathrm{O}_{3}$ powder $(0.3 \mu \mathrm{m}$ particle size $)$ to assure a close contact between the specimen and the pressure bars of the SHPB apparatus during impact testing. Finally, the two ends of the specimen were lubricated with molybdenum disulfide grease to minimize friction effects. 


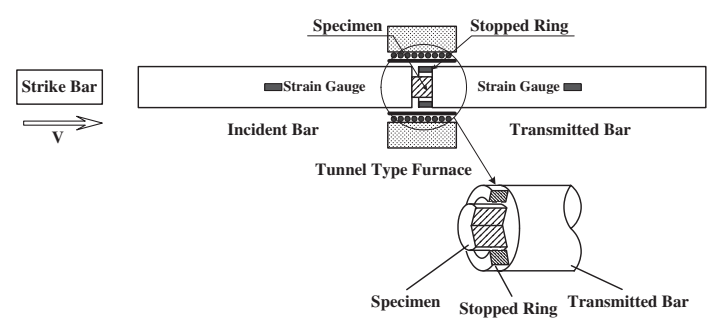

Fig. 1 Schematic illustration of compressive type split-Hopkinson bar with high temperature furnace.

The dynamic impact tests were performed using a compressive SHPB system at strain rates of $8 \times 10^{2} \mathrm{~s}^{-1}$, $3 \times 10^{3} \mathrm{~s}^{-1}$ and $8 \times 10^{3} \mathrm{~s}^{-1}$ and temperatures of $25^{\circ} \mathrm{C}$, $300^{\circ} \mathrm{C}, 500^{\circ} \mathrm{C}, 700$ and $900^{\circ} \mathrm{C}$, respectively. Figure 1 presents a schematic illustration of the experimental apparatus. As shown, the SHPB system basically comprised an incident bar, a transmitted bar and a strike bar. The bars were all made of DC53 die steel and had a diameter of $13 \mathrm{~mm}$. The incident and transmitter bars each had a length of $1 \mathrm{~m}$. During testing, the specimen was placed between the incident and transmitted bars, and the incident bar was then impacted by the strike bar. The resulting compressive wave propagated along the incident bar until it reached the interface with the specimen, at which point, part of the wave was reflected back along the incident bar, while the remainder was transmitted through the specimen and into the transmitted bar. The amplitudes of the reflected wave $\left(\varepsilon_{r}\right)$ and the transmitted wave $\left(\varepsilon_{t}\right)$ were recorded using SR-4 strain gauges mounted on the incident bar and the transmitted bar, respectively. To ensure that the specimens fractured under the initial impact of the compressive pulse, and to prevent a reloading effect, a stopped ring was fitted around the test specimen. (Note that the use of stopped rings in SHPB testing is fully described in 21 ) and 22), and hence the details are omitted here). Based on one-dimensional elastic wave propagation theory, the strain $(\varepsilon)$, strain rate $(\dot{\varepsilon})$ and flows stress $(\sigma)$ in the specimen was obtained from the measured values of the reflected wave amplitude $\left(\varepsilon_{r}\right)$ and transmitted wave amplitude $\left(\varepsilon_{t}\right)$ via the following formulae

$$
\begin{aligned}
\varepsilon & =\frac{-2 C_{0}}{L} \int \varepsilon_{r} d t, \\
\dot{\varepsilon} & =\frac{-2 C_{0}}{L} \varepsilon_{r} \\
\sigma & =\frac{E A}{A_{S}} \varepsilon_{t}
\end{aligned}
$$

where $C_{0}$ is the longitudinal-wave velocity in the incident and transmitted bars, $L$ is the effective gauge length of the specimen, $E$ is the Young's modulus of the incident and transmitted bars, and $A$ and $A_{S}$ are the cross-sectional areas of the bars and the specimen, respectively.

In the impact tests performed at temperatures of $300^{\circ} \mathrm{C}$ or higher, the specimen was heated using a tunnel type electric furnace. As shown in Fig. 1, the ends of the incident and transmitter bars extended into the furnace, and hence thermal gradients were induced along the length of each bar. These temperature gradients not only affect the rate of pulse propagation in the bars, but also change the Young's modulus value of the DC53 die steel. The effect of the thermal gradients must therefore be taken into account by modifying the original equations for the specimen strain, strain rate and stress derived for testing at room temperature, i.e. eqs. (1) (3). The current high temperature impact testing technique and the modified stress and strain calculations are fully documented by Chiddister and Malvern in Ref. 23) and by the current group in Ref. 24).

Following impact testing, the fractured specimens were prepared for metallographic observations. Specimens for optical microscopy (OM) observation were mounted in Metaserve DAP moulding powder and were then ground using 400, 800 and 1200 series grit paper. The ground specimens were polished with a microcloth using a slurry containing $0.3 \mu \mathrm{m}$ alumina particles and were then etched in a solution of $\mathrm{HF}: 2 \mathrm{~mL}, \mathrm{HNO}_{3}: 3 \mathrm{~mL}, \mathrm{H}_{2} \mathrm{O}: 95 \mathrm{~mL}$ for $40 \mathrm{~s}$. The finished specimens were observed using a Axiovert 200MAT optical microscope. The fracture surface features of the deformed specimens were examined using scanning electron microscopy (SEM). Specimens were prepared using standard metallographic procedures and were observed using a JEOL JX A-840 scanning electron microscope operated at $15 \mathrm{kV}$.

\section{Results and Discussion}

\subsection{Stress-strain characteristics}

Figures 2 (a) $\sim(e)$ present the dynamic stress-strain curves of $\mathrm{Ti}$ alloy deformed at strain rates of $8 \times 10^{2} \mathrm{~s}^{-1}, 3 \times$ $10^{3} \mathrm{~s}^{-1}$ and $8 \times 10^{3} \mathrm{~s}^{-1}$ at temperatures of $25^{\circ} \mathrm{C}, 300^{\circ} \mathrm{C}$, $500^{\circ} \mathrm{C}, 700^{\circ} \mathrm{C}$ and $900^{\circ} \mathrm{C}$, respectively. In general, it is observed that the stress increases with increasing strain rate, but decreases with increasing temperature. In every instance, the flow stress increases with increasing strain during the initial stage of deformation. However, having reached a peak value, the stress reduces as the strain is increased further. It is thought that this reduction in stress takes place when the strain and strain rate hardening effect is outweighed by the softening effect induced by the heat generated during plastic deformation. The obvious difference in the flow stress between the stress-strain curves obtained under different loading conditions indicates that the mechanical properties of Ti alloy are highly dependent on both the strain rate and the temperature.

Figure 3 illustrates the variation of the fracture strain $\left(\varepsilon_{\mathrm{f}}\right)$ and the strain at maximum stress $\left(\varepsilon_{\mathrm{m} \sigma}\right)$ with the temperature. It is observed that for a constant temperature, $\varepsilon_{\mathrm{m} \sigma}$ increases with increasing strain rate. In other words, the strengthening effect induced by a higher strain rate delays the onset of thermal softening. Meanwhile, for a given strain rate, $\varepsilon_{\mathrm{m} \sigma}$ reduces as the test temperature is increased from $25^{\circ} \mathrm{C}$ to $700^{\circ} \mathrm{C}$, but increases when the temperature is increased to $900^{\circ} \mathrm{C}$. The higher value of $\varepsilon_{\mathrm{m} \sigma}$ at $900^{\circ} \mathrm{C}$ may be a result of a change in the microstructure at temperatures higher than the $\beta$ transus temperature $\left(785^{\circ} \mathrm{C}\right)$. In the current impact tests, not all of the strain rate and temperature conditions result in specimen failure. For example, Figure 2 shows that of those specimens tested at the lowest strain rate of $8 \times 10^{2} \mathrm{~s}^{-1}$, only the specimen deformed at a temperature of $25^{\circ} \mathrm{C}$ fractured. For those specimens tested at strain rates of $3 \times 10^{3} \mathrm{~s}^{-1}$ and $8 \times 10^{3} \mathrm{~s}^{-1}$, the tendency of the fracture strain $\left(\varepsilon_{\mathrm{f}}\right)$ with 


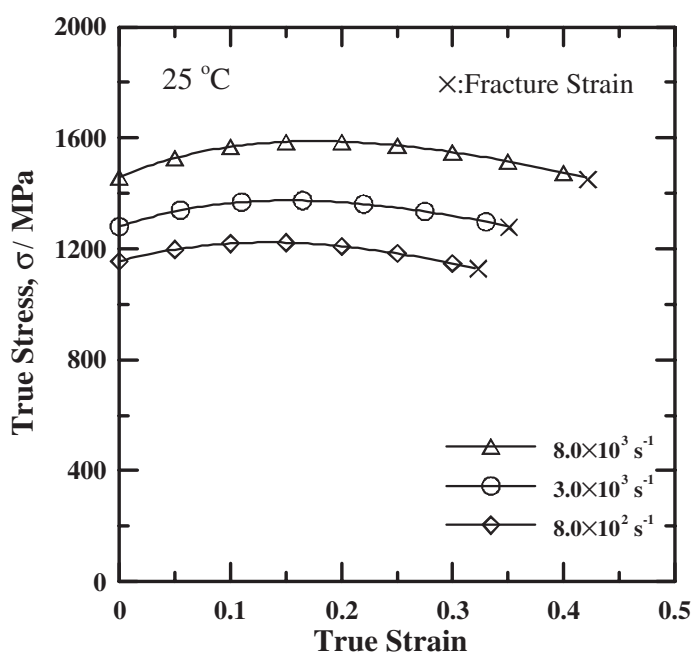

(a)

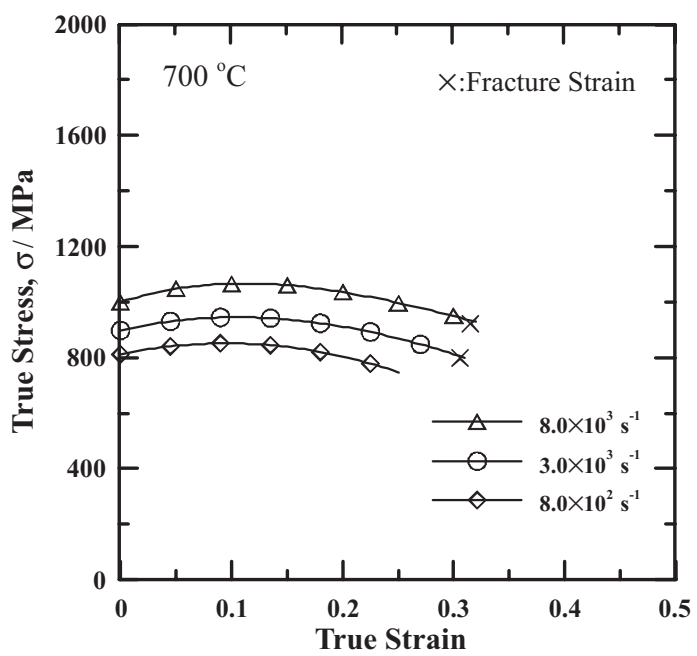

(c)

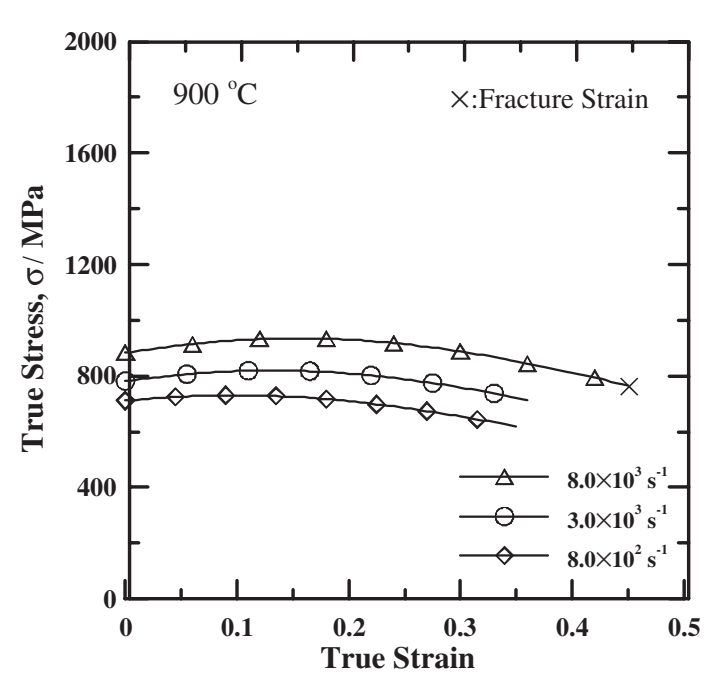

(e)

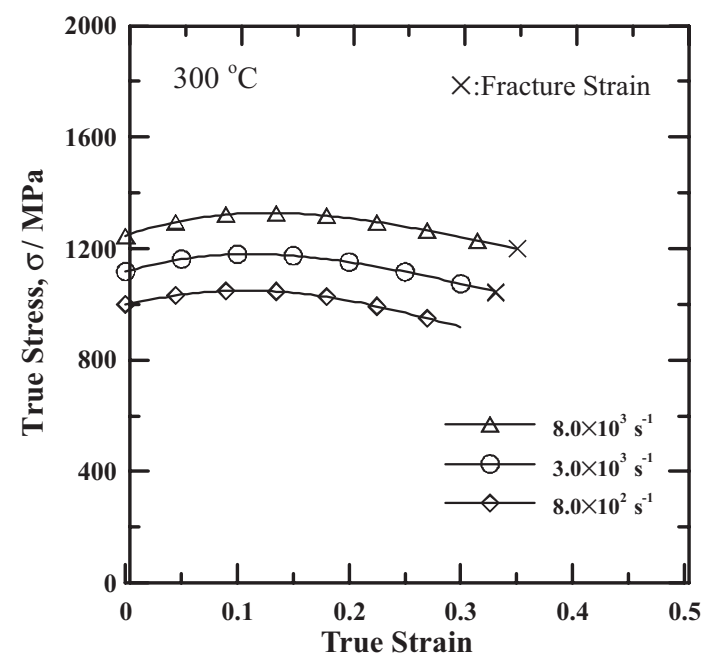

(b)

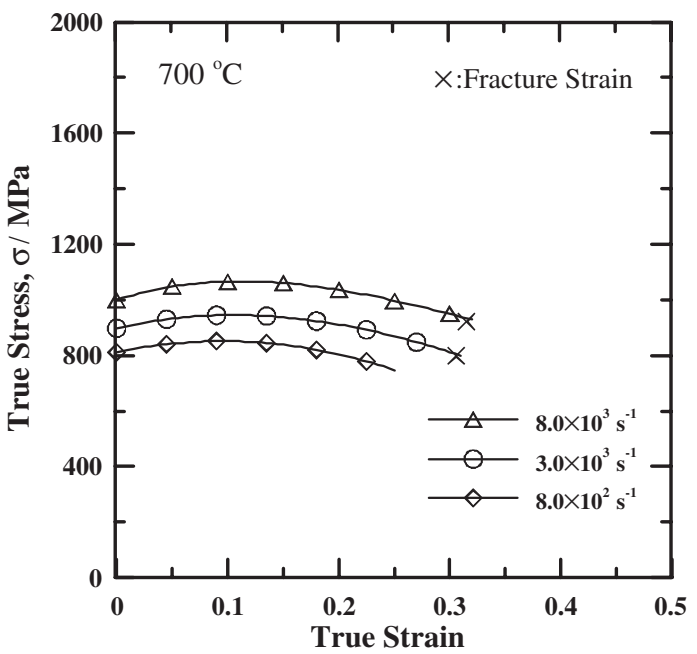

(d)

Fig. 2 Stress-strain curves of Ti alloy as function of strain rate at temperatures of: (a) $25^{\circ} \mathrm{C}$, (b) $300^{\circ} \mathrm{C},(\mathrm{c}) 500^{\circ} \mathrm{C}$, (d) $700^{\circ} \mathrm{C}$ and (e) $900^{\circ} \mathrm{C}$. 


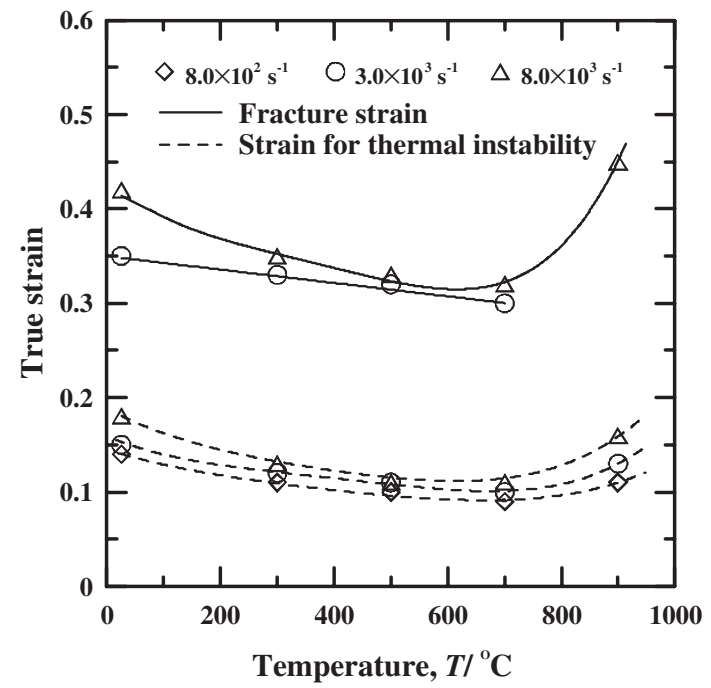

Fig. 3 Variation of fracture strain $\left(\varepsilon_{\mathrm{f}}\right)$ and strain at maximum stress $\left(\varepsilon_{\mathrm{m} \sigma}\right)$ with temperature as function of strain rate.

increasing temperature is similar to that of the strain at maximum stress $\left(\varepsilon_{\mathrm{m} \sigma}\right)$, i.e. $\varepsilon_{\mathrm{f}}$ reduces with increasing temperature at temperatures lower than $700^{\circ} \mathrm{C}$, but increases significantly at a temperature of $900^{\circ} \mathrm{C}$ (highest strain rate specimen only).

The temperature-dependent variation of the fracture strain is thought to be related to the amount of $\alpha$ phase in the deformed microstructure. As discussed below, the volume of $\alpha$ phase increases with increasing temperature prior to phase transformation at the $\beta$ transus temperature (i.e. $T_{\beta}=$ $785^{\circ} \mathrm{C}^{25)}$ ), but dissolves entirely at higher temperatures and is replaced by a pure $\beta$ phase. Figures 4(a) and 4(b) present optical microscope images of the undeformed $\mathrm{Ti}$ alloy microstructure at temperatures of $25^{\circ} \mathrm{C}$ and $900^{\circ} \mathrm{C}$, respectively. In Fig. 4(a), the microstructure is composed of needlelike $\alpha$ phase distributed within the fine $\beta$ phase matrix. However, at $900^{\circ} \mathrm{C}$, the microstructure comprises polygonal grains, and clearly shows a transformation from the initial $\alpha+\beta$ phase (Fig. 4(a)) to a single $\beta$ phase since the temperature exceeds the $\beta$ transus temperature. As discussed above, the presence of a single $\beta$ phase at $900^{\circ} \mathrm{C}$ results in a significant increase in the fracture strain. Figures $4(\mathrm{c}) \sim 4(\mathrm{f})$ present TEM images of the Ti alloy microstructure deformed at temperatures of $25^{\circ} \mathrm{C}, 500^{\circ} \mathrm{C}, 700^{\circ} \mathrm{C}$ and $900^{\circ} \mathrm{C}$, respectively, under a constant strain rate of $8 \times 10^{3} \mathrm{~s}^{-1}$. The micrographs clearly show that the $\alpha$ phase increases with increasing temperature below $700^{\circ} \mathrm{C}$, but disappears entirely when the specimen is tested at $900^{\circ} \mathrm{C}$.

\subsection{Strain rate effect and Activation value}

To clarify the effect of the strain rate on the mechanical response of Ti alloy, Figure 5 plots the variation of the true stress with the strain rate as a function of the temperature and the true strain. Note that the strain values 0.1 and 0.2 correspond to the work hardening region and the work softening region, respectively. It is seen that the flow stress increases significantly with increasing strain rate in both work hardening regions. The effect of the strain rate on the flow stress can be quantified using a strain rate sensitivity parameter, $\beta$; equivalent to the gradient of the $\sigma$ vs. $\log \dot{\varepsilon}$ plot, i.e.

$$
\beta=\left(\sigma_{2}-\sigma_{1}\right) / \ln \left(\dot{\varepsilon}_{2} / \dot{\varepsilon}_{1}\right)
$$

where the compressive stresses $\sigma_{2}$ and $\sigma_{1}$ are obtained from impact tests conducted at average strain rates of $\dot{\varepsilon}_{2}$ and $\dot{\varepsilon}_{1}$, respectively, and are calculated at the same value of the compressive plastic strain. Figure 6(a) plots the value of the strain rate sensitivity parameter against the temperature as a function of the strain rate and the true strain. It is apparent that at a given temperature, the Ti alloy becomes increasingly sensitive to the strain rate at higher values of the true strain. Furthermore, although the stress-strain curves presented in Fig. 1 show both work hardening and work softening characteristics, the near equal increase in the strain rate sensitivity as the strain is increased from 0.1 to 0.2 in the lower strain rate range and the higher strain rate range, respectively, indicates that the work hardening type has no more than a minor influence on the strain rate sensitivity of the Ti alloy.

At lower strain rates, the strain rate sensitivity reduces linearly with increasing temperature. However, at higher strain rates, the strain rate sensitivity falls rapidly with increasing temperature at temperatures lower than $300^{\circ} \mathrm{C}$, but reduces more slowly as the temperature is increased toward $900^{\circ} \mathrm{C}$. In other words, for plastic deformation performed under high strain rate loading conditions, Ti alloy is more strain rate sensitive at lower temperatures. Assuming that the deformation process is dominated by a thermally activated deformation mechanism in the high strain rate regime, the variation of the activation volume, $v^{*}$, is related directly to the flow stress and the strain rate. The value of $v^{*}$ can be calculated from the strain rate sensitivity parameter via the following equation: ${ }^{26)}$

$$
v^{*}=K_{b} T\left[\left(\ln \dot{\varepsilon}_{2} / \dot{\varepsilon}_{1}\right) /\left(\sigma_{2} / \sigma_{1}\right)\right]_{\mathrm{T}}=K_{b} T / \beta
$$

where $K_{b}$ is the Boltzmann constant $\left(1.38 \times 10^{-23} \mathrm{~J} / \mathrm{K}\right)$ and $\mathrm{T}$ is the absolute temperature. Figure 6(b) illustrates the variation of the activation volume of $\mathrm{Ti}$ alloy with the temperature under the current strain rate conditions. Note that the values of $v^{*}$ plotted in this figure are normalized with respect to $b^{3}$, where $\mathrm{b}$ is the Burger vector and has a value of $0.29 \mathrm{~nm}$ for the current alloy. As shown, $v^{*}$ increases with increasing temperature, but reduces with increasing strain and strain rate.

\subsection{Temperature effect}

To clarify the effect of the temperature on the mechanical behaviour of Ti alloy, Figure 7(a) illustrates the variation of the flow stress with the testing temperature as a function of the strain rate at true strains of 0.1 and 0.2 , respectively. In general, the reduction in the flow stress with increasing temperature confirms that the alloy is temperature sensitive. Although there is no obvious reduction in the flow stress as the temperature is increased from $500^{\circ} \mathrm{C}$ to $700^{\circ} \mathrm{C}$, the flow stress falls rapidly as the temperature is increased further to $900^{\circ} \mathrm{C}$. As shown in Table 1 and Fig. 2, the lowest fracture strain occurs at a temperature of $700^{\circ} \mathrm{C}$. Hence, it appears that the $\beta$ transus temperature $\left(785^{\circ} \mathrm{C}\right)$ represents a critical temperature threshold at which an obvious change in the 

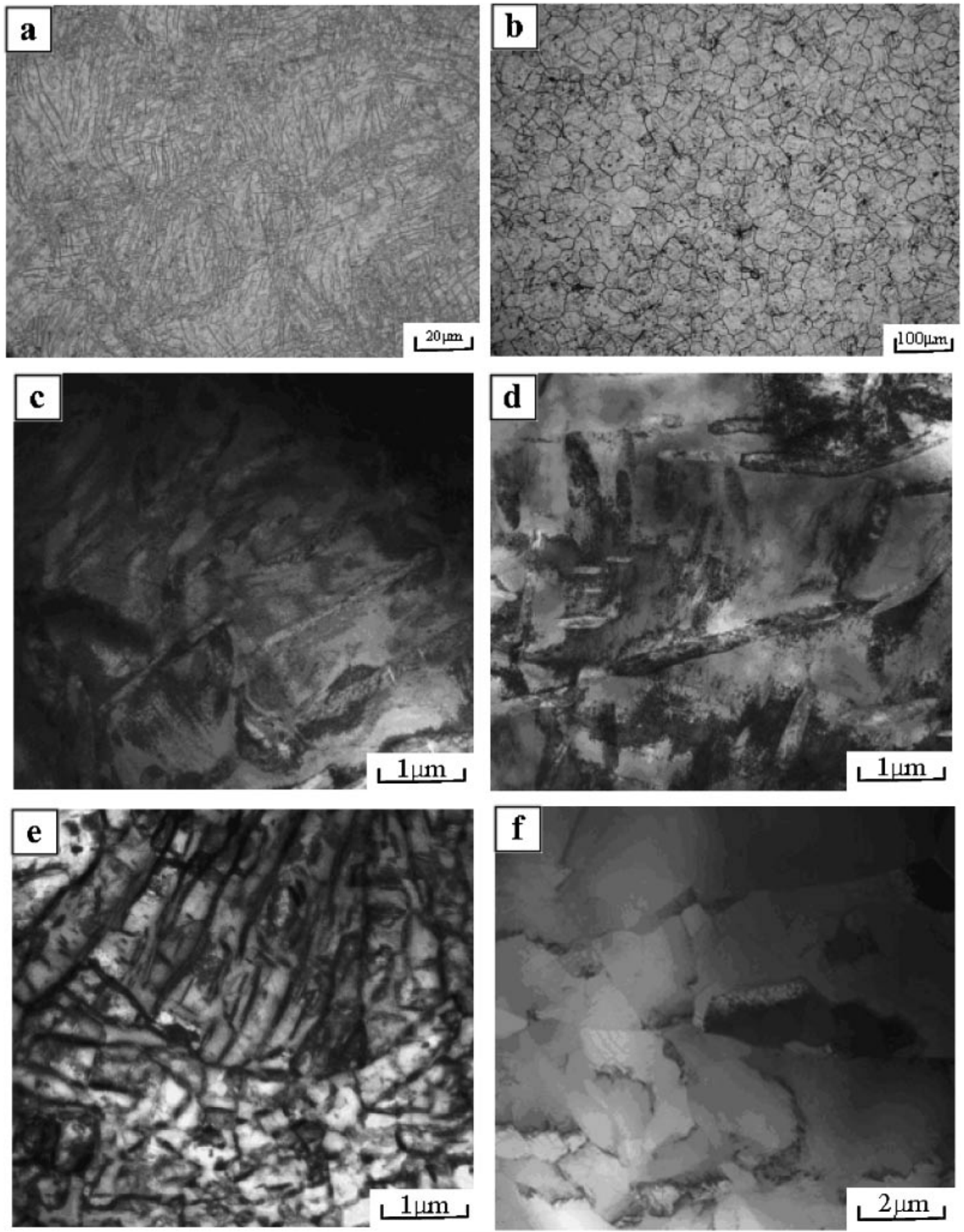

Fig. 4 Optical microstructures of undeformed Ti alloy at (a) $25^{\circ} \mathrm{C}$; (b) $900^{\circ} \mathrm{C}$; TEM micrographs of specimens deformed at strain rate of $8 \times 10^{3} \mathrm{~s}^{-1}$ under temperatures of (a) $25^{\circ} \mathrm{C}$; (b) $500^{\circ} \mathrm{C}$; (c) $700^{\circ} \mathrm{C}$ and (d) $900^{\circ} \mathrm{C}$.

microstructure (and hence the mechanical behaviour, e.g. the flow stress) of the alloy takes place.

The temperature effect can be quantified via the temperature sensitivity parameter $n_{a}$; defined as $n_{a}=$ $\ln \left(\sigma_{2} / \sigma_{1}\right) / \ln \left(T_{2} / T_{1}\right)$, where the flow stresses $\sigma_{1}$ and $\sigma_{2}$ are obtained from impact tests conducted at constant temperatures of $T_{1}(293 \mathrm{~K})$ and $T_{2}$, respectively, under the same strain rate. Figure 7(b) illustrates the variation of $n_{a}$ with the temperature as a function of the strain rate and the true strain. For a given temperature, it is observed that $n_{a}$ increases with increasing strain and strain rate. This suggests that the heat generated during the plastic deformation process increases at higher values of the strain and strain rate. Furthermore, it can be seen that $\mathrm{Ti}$ alloy is highly sensitive to the temperature in the ranges $25^{\circ} \mathrm{C}$ to $500^{\circ} \mathrm{C}$ and $700^{\circ} \mathrm{C}$ to $900^{\circ} \mathrm{C}$, respectively. However, at temperatures between $500^{\circ} \mathrm{C}$ and $700^{\circ} \mathrm{C}, n_{a}$ has an approximately constant value, which indicates that the temperature effect at $700^{\circ} \mathrm{C}$ is suppressed until the temperature increases beyond the $\beta$ transus temperature $785^{\circ} \mathrm{C}$.

\subsection{Fracture feature observations}

The current fractured specimens all show signs of macroscopic localised shearing. Figure 8(a) presents a low magnification micrograph of a specimen tested at a temperature 


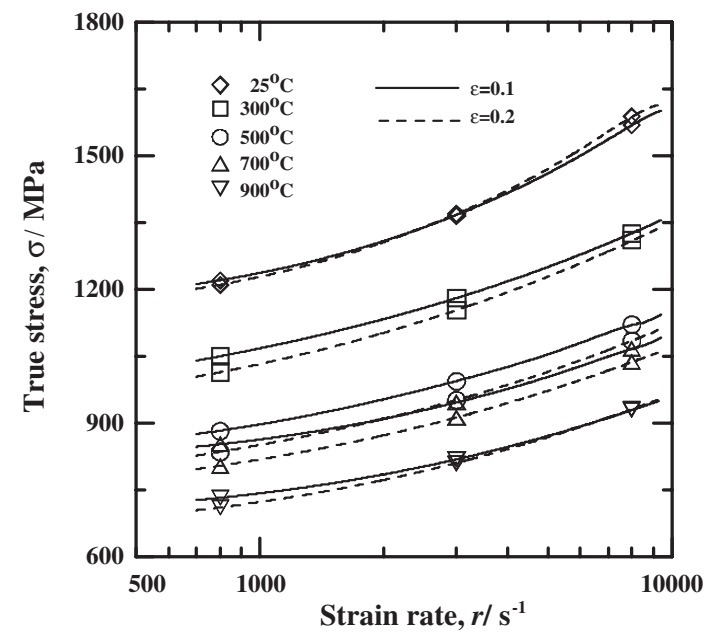

Fig. 5 Variation of flow stress with strain rate as function of temperature at true strains of 0.1 and 0.2 .

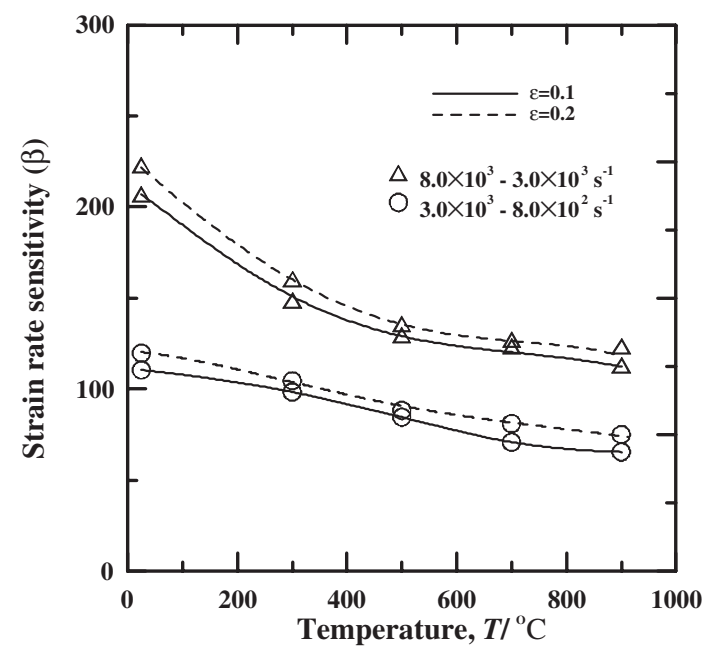

(a)

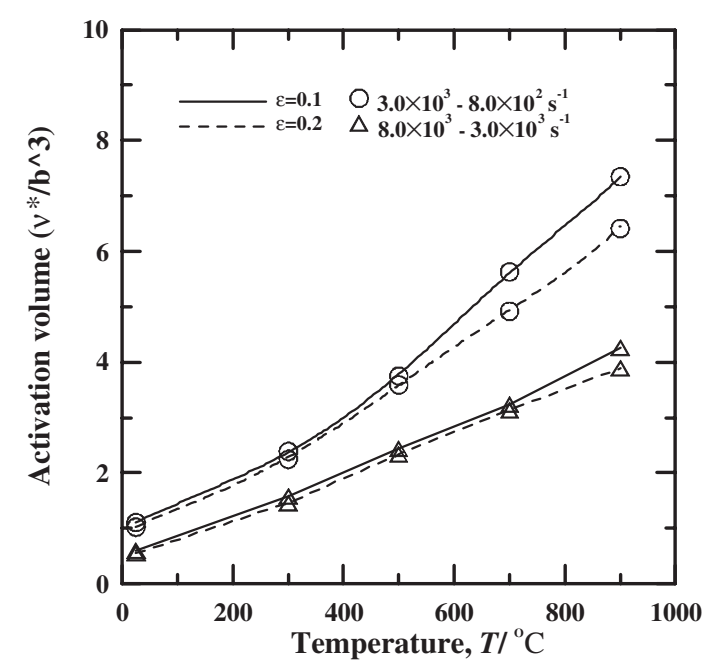

(b)

Fig. 6 Variation of (a) strain rate sensitivity and (b) activation volume as function of strain rate at true strains of 0.1 and 0.2 .

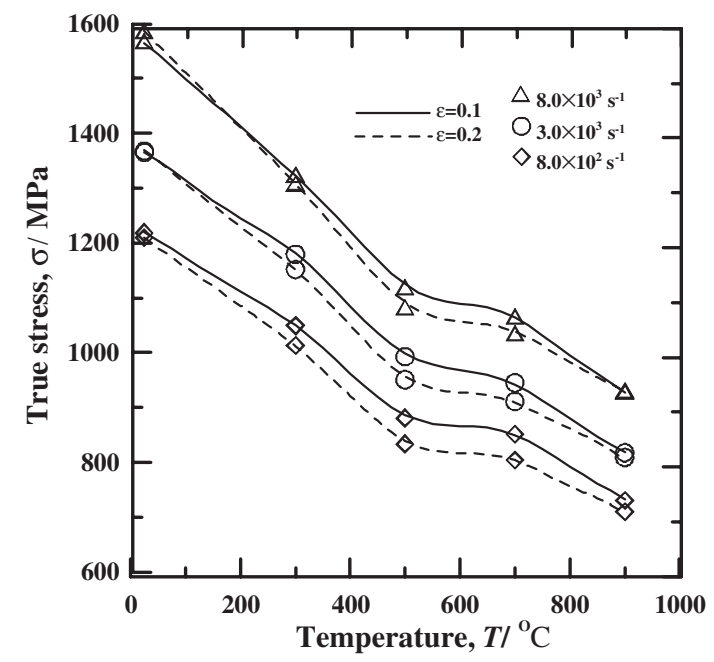

(a)

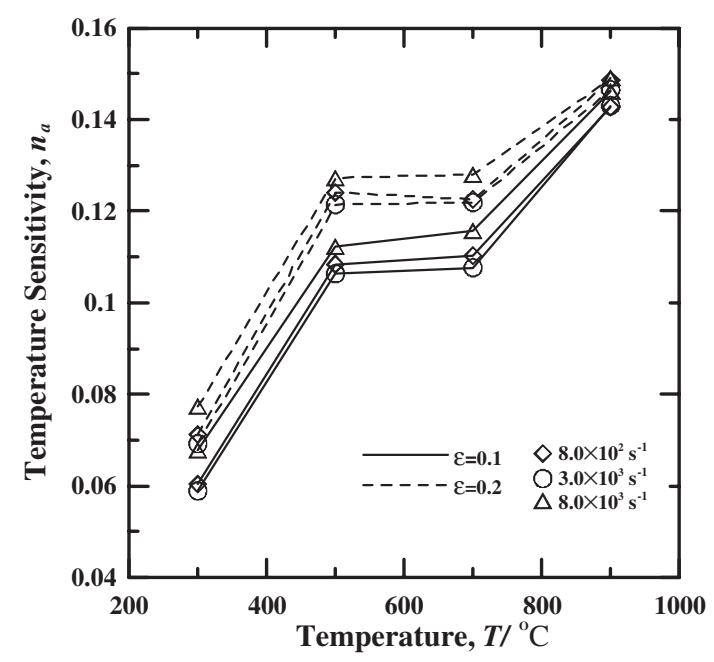

(b)

Fig. 7 Variation of (a) flow stress and (b) temperature sensitivity with temperature as function of strain rate at true strains of 0.1 and 0.2 .

of $25^{\circ} \mathrm{C}$ and a strain rate of $8 \times 10^{3} \mathrm{~s}^{-1}$. It can be seen that the specimen failed in a catastrophic manner along a plane orientated at an angle of $40 \sim 50^{\circ}$ to the compression axis. Figure 8(b) shows the fragmentation features of the failed specimen in Fig. 8(a). It is observed that adiabatic shear bands form near the periphery of the two end faces of the specimen and then penetrate into the bulk material, where they subsequently meet at the centre of the specimen. The adiabatic shear bands observed on transverse cross section of the specimen have the form of an arc. As a result, the shear bands on the fracture surface of the fragmented specimen form two cone-like structures. Figure $8(\mathrm{c})$ presents a schematic representation of the fracture features, in which these cone structures are clearly marked. Figure 8(d) shows a metallographic cross-section (parallel to the compression axis) of a specimen deformed at a temperature of $25^{\circ} \mathrm{C}$ and a strain rate of $8 \times 10^{3} \mathrm{~s}^{-1}$. It can be seen that the microstructural deformation is inhomogeneous, and is particularly intense in the central region of the specimen. In the current study, specimen fracture occurs as the result of intensive localised shear flow prompted by the formation of shear 


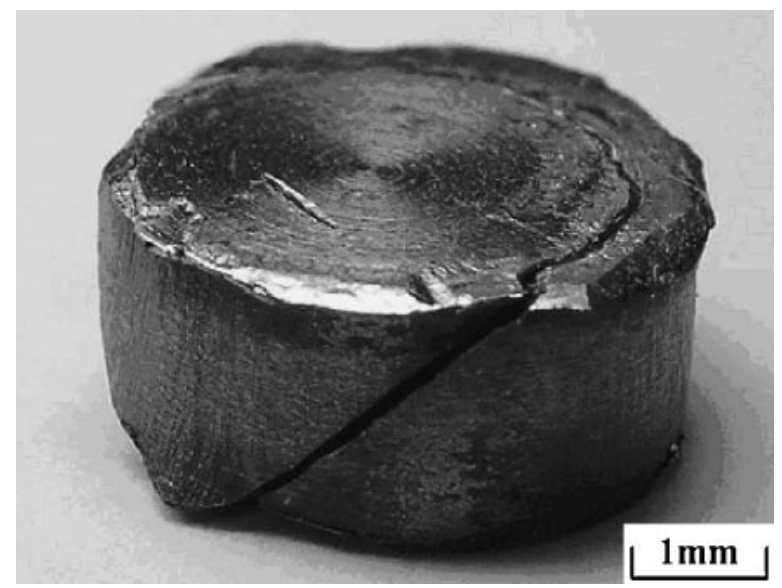

(a)

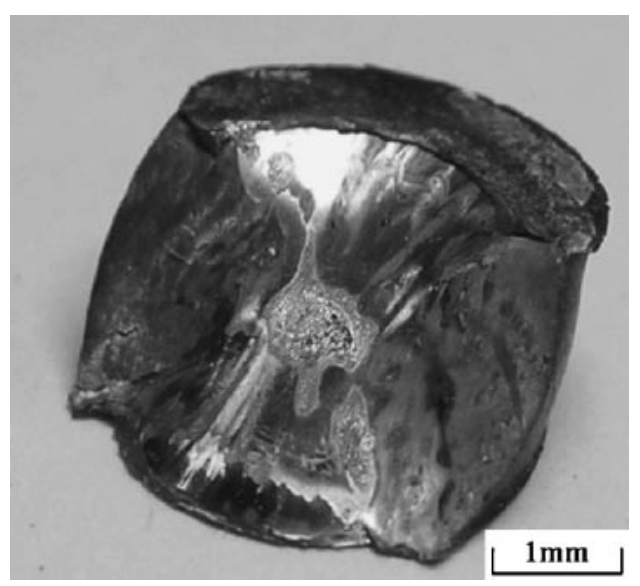

(b)

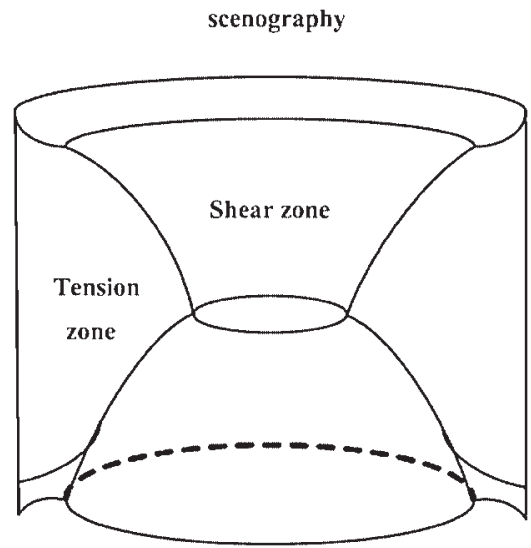

(c)

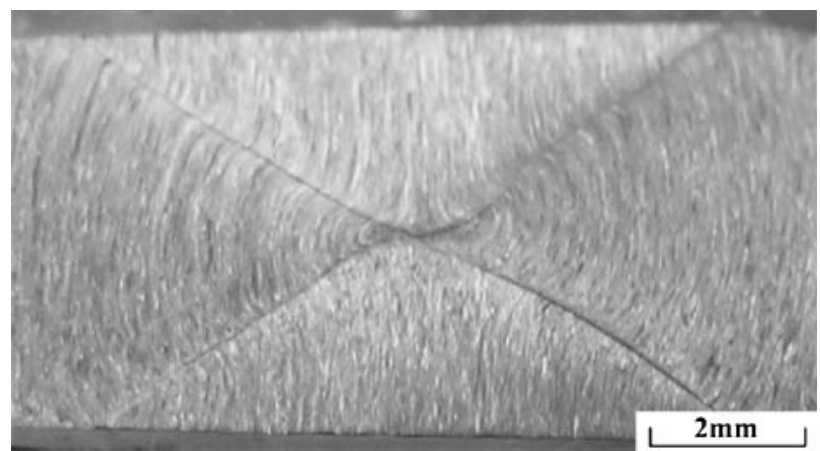

(d)

Fig. 8 (a) Low magnification SEM fractograph of specimen deformed at $8 \times 10^{3} \mathrm{~s}^{-1}$ and $25^{\circ} \mathrm{C}$; (b) fractograph of specimen which broke into two identical fragments during impact; (c) schematic illustration of fracture feature in failed specimen during impact; (d) Metallographic cross sections taken from the specimen deformed at $8 \times 10^{3} \mathrm{~s}^{-1}$ and $25^{\circ} \mathrm{C}$.

bands. The inhomogeneous deformation of the microstructure results in an X-like arrangement of these shear bands, as shown in Fig. 8(d). This pattern is reminiscent of the slip field solution, in which the slip lines are aligned with the maximum shear stress and maximum shear strain directions, respectively.

The current fractographic observations show that the specimens fail as a result of separation along the adiabatic shear band. An array of tiny microcracks are commonly observed within the adiabatic shear band. Figures 9(a) 9(f) present SEM fractographs of specimens deformed under various strain rate and temperature conditions. In every case, it can be seen that the fracture features comprise two main characteristics, namely a relatively smooth surface corresponding to a brittle fracture and a dimple-like structure corresponding to a ductile fracture. Furthermore, in the specimens tested at a high strain rate and temperatures higher than $300^{\circ} \mathrm{C}$, "splat-like" deposits and "knobbly" structures are observed on the adiabatic shear band fracture surfaces, as shown in Figs. 9(b) through 9(e). Figure 9(f) presents a high 

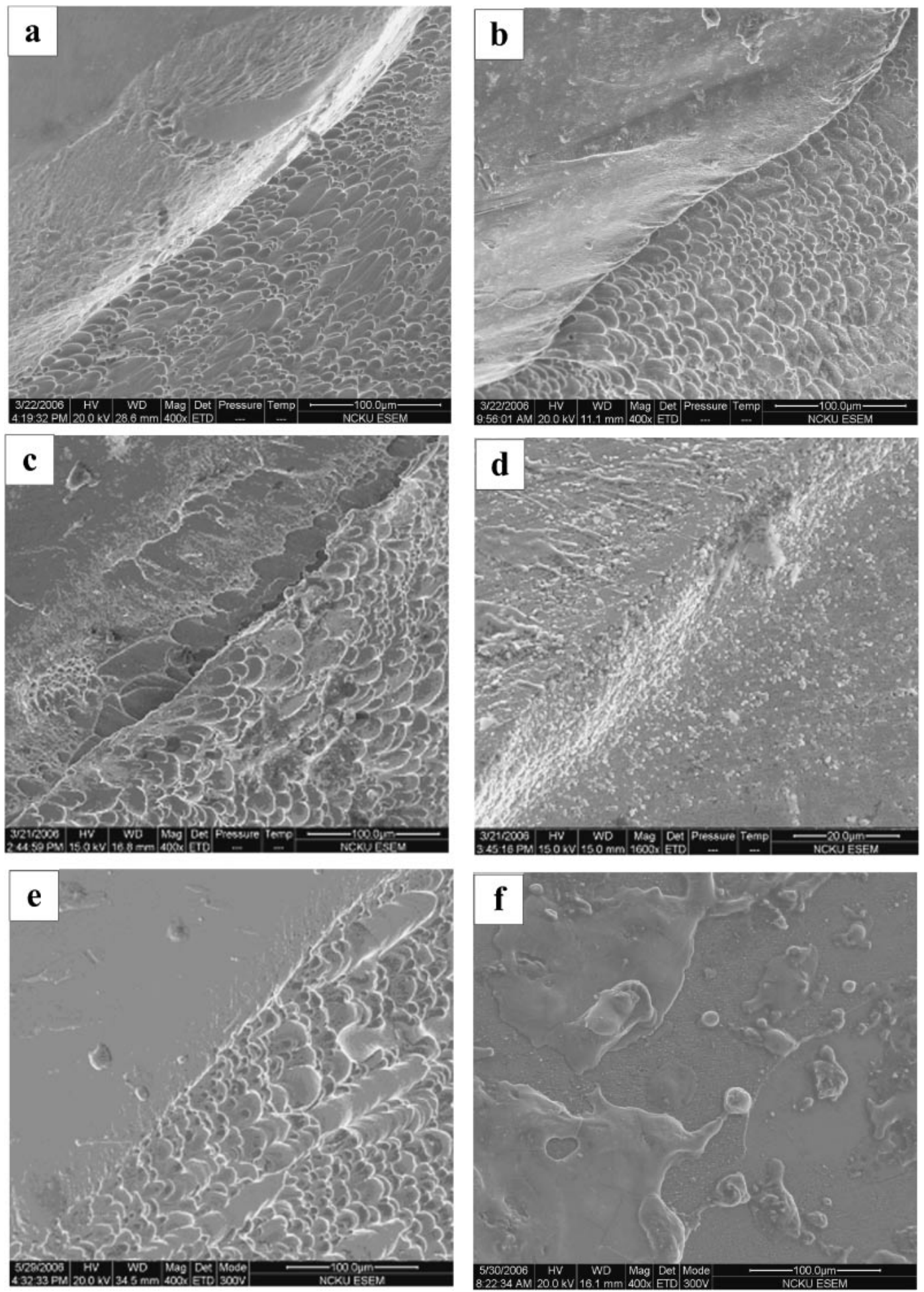

Fig. 9 Scanning electron micrographs of fractured surface due to adiabatic shearing for Ti alloy deformed at $8 \times 10^{3} \mathrm{~s}^{-1}$ under temperatures of (a) $25^{\circ} \mathrm{C}$; (b) $300^{\circ} \mathrm{C}$; (c) $500^{\circ} \mathrm{C}$; (d) $700^{\circ} \mathrm{C}$; (e) $900^{\circ} \mathrm{C}$; (f) splats and knobbles within adiabatic shear band of Fig. 9 (e).

magnification view of the splats and knobble features formed on the fracture surface of the specimen shown in Fig. 9(e). The presence of these features indicates that a significant melting of the original shear band material takes place prior to fracture.

Comparing the matrix dimple structure of Fig. 9(a) through (d), it is found that the dimple size increases, but dimple density decrease as the temperature increases. This result provides a reasonable explanation for the loss of ductility in the present titanium alloy with increasing temperature at temperature lower than $700^{\circ} \mathrm{C}$. However, for the specimen deformed at a temperature of $900^{\circ} \mathrm{C}$, Fig. 9(e), the fracture surface of matrix has a high dimple density due to the presence of a single $\beta$ phase, indicating a significant increase in the fracture strain. The observed dimple structure is entirely consistent with the stress-strain tendencies presented in Fig. 2(a) through 2(e). 
Table 1 Mechanical properties of Ti-15Mo-5Zr-3Al alloy deformed at strain rates ranging from $800 \mathrm{~s}^{-1}$ to $8000 \mathrm{~s}^{-1}$ and temperatures ranging from $25^{\circ} \mathrm{C}$ to $900^{\circ} \mathrm{C}$

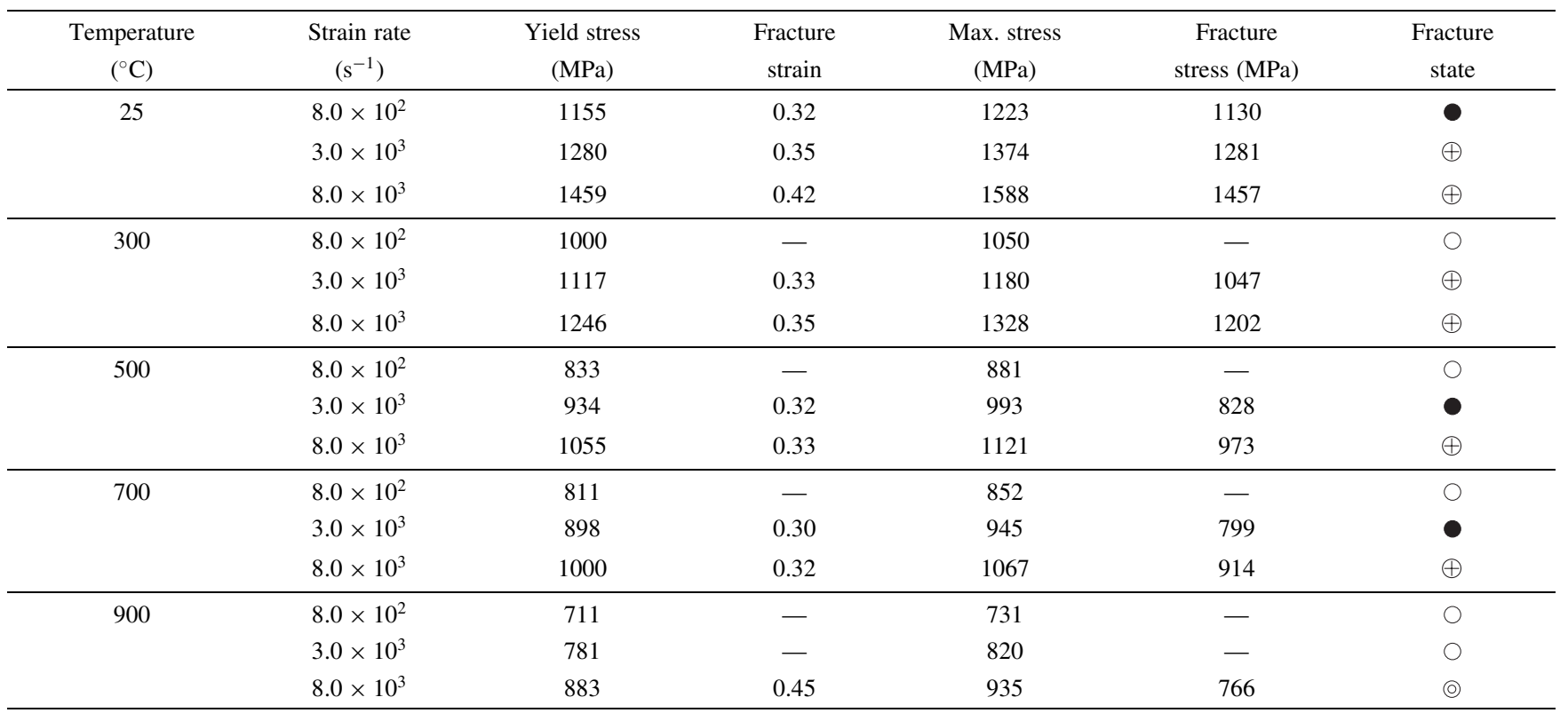

:Safe; $\bigcirc$ :Single shear band; $\oplus$ : Single shear band with crack; @ :Multiple shear bands with crack

\section{Conclusions}

This study has investigated the dynamic mechanical response and fracture behaviour of $\mathrm{Ti}$ alloy deformed under strain rates of $8 \times 10^{2} \mathrm{~s}^{-1}, 3 \times 10^{3} \mathrm{~s}^{-1}$ and $8 \times 10^{3} \mathrm{~s}^{-1}$ at temperatures of $25^{\circ} \mathrm{C}, 300^{\circ} \mathrm{C}, 500^{\circ} \mathrm{C}, 700^{\circ} \mathrm{C}$ and $900^{\circ} \mathrm{C}$. The results have shown that the stress-strain response and fracture behaviour of this alloy are highly sensitive to both the strain rate and the temperature. In general, the flow stress increases with an increasing strain rate and a decreasing temperature. Furthermore, for a given temperature, the fracture strain increases with an increasing strain rate. For a given strain rate, the lowest value of the fracture strain is observed at a temperature of $700^{\circ} \mathrm{C}$. The strain rate sensitivity increases with increasing strain and strain rate, but decreases with increasing temperature. By contrast, the activation volume reduces as the strain and strain rate are increased, but increases as the temperature is increased. The fractographic results reveal that adiabatic shearing is the primary cause of specimen failure under the current testing conditions. The fracture features of the current specimens include ductile dimple-like structures in the matrix and brittle cleavage structures within the adiabatic shear band. A direct correlation is found between the depth and density of the dimples and the magnitude of the fracture strain.

\section{REFERENCES}

1) I. Gurappa: Mater. Sci. Eng. A356 (2003) 372-380.

2) K. Wang: Mater. Sci. Eng. A213 (1996) 134-137.
3) H. M. Kim, H. Takadama, T. Kokubo, S. Nishiguchi and T. Nakamura: Biomaterials 21 (2000) 353-358.

4) U. S. Lindholm: J. Mech. Phys. Sol. 12 (1964) 317-335.

5) P. S. Follansbee: Metals Handbook. Mechanical Testing, J. R. Newby (Ed.), Vol. 8, 9th ed., (ASM, ohio, 1985), pp. 190-192.

6) Y. B. Xu, W. L. Zhong, Y. J. Chen, L. T. Shen, Q. Lin, L. Y. Bai and M. A. Meyers: Mater. Sci. Eng. A229 (2001) 287-295.

7) W. S. Lee and T. H. Chen: Scripta Mater. 54 (2006) 1463-1468.

8) G. Regazzoni and U. F. Kocks: P. S. Follansbee: Acta Metall. 35 (1987) 2865-2875.

9) W. S. Lee and C. F. Lin: Mater. Sci. Eng. A308 (2001) 124-135.

10) Y. Lin, J. Zhu and H. Zhou: Metall. Trans. 23A (1992) 335-340.

11) W. S. Lee and C. Y. Liu: Mater. Sci. Eng. A426 (2006) 101-113.

12) H. C. Rogers: Ann. Rev. Matr. Sci. 9 (1979) 283-311.

13) A. E. Bayoumi and J. Q. Xie: Mater. Sci. Eng. A190 (1995) 173-180.

14) K. Cho, Y. C. Chi and J. Duffy: Metall. Trans. 21A (1990) 1161-1175.

15) S. C. Liao and J. Duffy: J. Mech. Phys. Solids, 46 (1998) 2201-2231.

16) R. Nakkalil, J. R. Hornaday Jr and M. N. Bassim: Mater. Sci. Eng. A141 (1991) 247-260.

17) Y. L. Bai and B. Dodd: Adiabatic Shear Localization, 1st ed., (Pergamon, Oxford, UK, 1992), pp. 155-193.

18) Y. Okazaki: Biomaterials 23 (2002) 2071-2077.

19) K. Tokaji and H. Kariya: Mater. Sci. Eng. A281 (2000) 268-274.

20) K. Tokaji, H. Shiota and J. C. Bian: Mater. Sci. Eng. A243 (1998) 155162.

21) T. Shirakashi, K. Maekawa and E. Usui: Bull. Jpn. Soc. Prec. Eng. 17 (1983) 161-166.

22) G. L. Wulf: Int. J. Mech. 20 (1978) 609-615.

23) J. L. Chiddister and L. E. Malvern: Exp. Mech. 3 (1963) 81-90.

24) W. S. Lee and C. F. Lin: Mater. Sci. Eng. A241 (1998) 48-59.

25) K. Tokaji, H. Shiota and J. C. Bian: Mater. Sci. Eng. A243 (1998) 155162.

26) F. Appel, U. Lorenz, M. Oehring, U. Sparka and R. Wagner: Mater. Sci. Eng. A233 (1997) 1-14. 